\title{
Research on the Upgrading Mechanism of Industrial Cluster Genetic Algorithm Model--Based on New Perspective of Business Unit
}

\author{
AiPing Qiao ${ }^{1,2}$ \\ ${ }^{1}$ School of Economics and Management South east University ,Nanjing 210096,China; \\ ${ }^{2}$ School of computer Science, Nanjing Normal university ,Nanjing 210023,China
}

Keywords: Industrial cluster, Genetic algorithm, Business unit

\begin{abstract}
This paper, through establishing a genetic algorithm model by integrating the theory of business unit rebuilding and resource theory, has discussed the function mechanism of the driving mechanism of business units on the industrial clusters. Since the process of selecting the model was practiced from two aspects, both of the internal resource allocation of business units and the external market were taken into account. Besides the quantity, cost, economic benefits and other variable tradeoff relations, earnings of business units were also be taken into consideration to the configuration of business units of this model. Then the business units of the industrial cluster were rebuilt through studying how the above-mentioned factors influence business units and according to earnings of business units until the upgrade-ing of the industrial cluster was realized. This paper has, not only enriched theories on industrial cluste-rs, but also provided new ideas for the government to lead the development of industrial clusters.
\end{abstract}

\section{Introduction}

Recently, industrial cluster is facing internal and external challenges. On one hand, many problems have sprung up, such as the risen labor cost, the resource shortage and pressure on environmental protection. On the other hand, some problems have become severe, such as the pressure from external international competition, global division of labor and embedded global value chain[1,2]. In such context, research on the mechanism of driving the upgrading of industrial cluster is helpful for further understanding the decision-making mechanism, along with innovative behaviors and formulation of governmental policies, of technological research and development in clusters Many scholars have conducted profound discussions on factors for driving cluster upgrading[3,4,5,6]. Currently, researches on industrial cluster upgrading have been stated from two major aspects: first, external factors of industrial cluster, such as the upgrading of external value chain, geographical and cultural factors, and environmental regulation; second, internal industrial cluster factors, including social responsibility of an enterprise, cluster growth, organizational learning and network relationships. Hou Erju(et.al.) has studied the upgrading of industrial cluster by basing on the driving mechanism[7]. Through trying to classify the internal and external driving mechanisms of industrial clusters, Hou Erju(et.al.) has come to a conclusion that the driving force of cluster upgrading is to a great extent from internal factors. Wang Jiaoli has discussed the upgrading mechanism from internal factors of industrial cluster[. Wang has established the four internal driving elements of cluster upgrading, they are: core enterprises; universities and research institutions; governmental institutions[8]; the knowledge network consists of productive service institutions and elements through interaction. Moreover, Some research has also analyzed the updating mechanism of driving elements of clusters in facilitating cluster upgrading[9,10,11,12]. The research indicates that the key to cluster upgrading is the functions of and matching among elements of the cluster knowledge network[13]. Hence, current researches are paying less attention to the driving mechanism of industrial cluster upgrading in the micro level or driving factors that are influencing industrial cluster innovation. In this paper, how the progress of planar reconstruction of business units influence the development path of industrial clusters was discussed. 
Moreover, the function mechanism of the internal driving mechanism of business units on industrial clusters was discussed through integrating the theory of business unit reconstruction and resource theory to construct a genetic algorithm model; besides that, how these factors are influencing policies of industrial clusters and how to adjust business units to facilitate cluster upgrading are studied.

\section{Industrial Cluster Model of Genetic Algorithms}

This paper, upon the model, has made a modification according to features of business units and assumed that business units in an industrial cluster are same in nature. The evolution process of the model covers the searching for business units with better performance or the replacement of business units of poor performance with business units of better performance so as to improving the benefits of the whole industrial cluster[14,15,16]. The model is limited in resource allocation and objective in the allocation of business units. Hence, the variables are under pressure and allocation principle in nature. In this case, consideration should be given to not only its quantity, cost, economic benefits and other variable trade-off relations, but also the overall performance of the business units. Selection process of the model is carried out from two aspects, during which both the allocation of resources in the business units and the external market should be taken into account. In this paper, factors for influencing the allocation of resources in business units are set:

This paper sets the internal resource allocation factors influence the business unit:

$E_{k}$ is the average cost of resources in different types of markets;

$H_{i k}$ is the number of resources categories $k$ in business units $i$;

$E_{i j}$ is the economic benefits of resources categories $j$ in business units $i$;

$T_{i j}$ is the existence duration of resources categories $j$ in business units $i$;

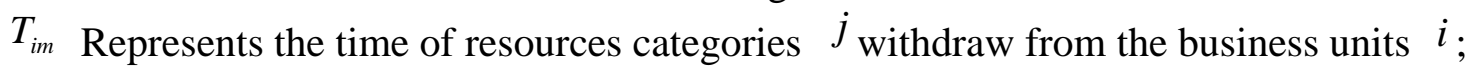

$F_{i j}$ is the decision support of resources categories $j$ in business units $i$;

$W_{j}$ is the attraction of business units to resources categories $j$;

This paper sets the effect factors of external market factors

$W_{m}$ is the attraction of business unit's competitors to resources categories $j$;

Among them

$i=1,2, \mathrm{~L}, m$ is the number of business units;

$j=1,2, \mathrm{~L}, n$ is the resources categories in business units;

Assume the business unit $i$ is the n-dimensional vector : $v_{i n}=\left\{v_{i 1}, v_{i 2}, \cdots, v_{i n}\right\}$,

$v_{i j}=1$ Represents that resources categories $j$ in business units $i$ is't used;

$v_{i j}=0$ Represents that resources categories $j$ in business units $i$ is not used;

$F_{i j}=1$ Represents the high level of decision support;

$F_{i j}=2$ Represents the moderate level of decision support;

$F_{i j}=3$ Represents the low level of decision support;

$\beta_{0}, \beta_{1}, \beta_{2}$ as parameters

$E X P_{i j}$ is evaluation function 


$$
E X P_{i j}=\beta_{0}\left(\sum_{k=1}^{n} E_{k} \cdot H_{i k}\right) \cdot \frac{W_{j} \cdot e^{-\beta_{1} T_{i j}+\beta_{2} F_{i j}}}{\sum_{m=1}^{n} W_{m} \cdot e^{-\beta_{1} T_{i m}+\beta_{2} F_{i m}}}
$$

The actual fitness function is $\sum \sum E X P_{i j}$

\section{Simulation and Analysis Model}

Initial population refers to 50 sample units that have been generated randomly. The number (50) of samples have been selected considering the convergence time and diversity of samples according to the number of parameters and length of genes. In this paper, it has been set that: $\beta_{0}=0.0002, \beta_{1}=0.02, \beta_{2}=0.05 ; E$ refers to a random value between 100 and $1000 ; \mathrm{H}$ refers to a random value between 40 and 3000; T refers to a random value between 6 and 360; W refers to a random value between 1 and 300; the number of competition units is 10. Randomly selected 30 units from the 50 sample units to form a sequence and calculated Exp of the sequence; repeated the above steps; selected for 500 times and caluculated to attain 500 sequences; selected 100 sequences with higher Exp's to conduct crossover and mutation in the next step. Divided the 100 sequences into 50 groups and conducted crossover between every two groups. Method of crossover: randomly selected 5 groups from the groups and required the 5 units to be different in state when selected (selected the first sequence and passed the second sequence Mutation is for changing the selected state of certain unit in certain sequence. The probability of mutation is 0.02 .Repeated steps select to mutation and conducted iteration for 10 times to attain the mean value of all data corresponding to every Exp .

Continuously increased the number of competition units after a better result was attained: increased by 5 competition units every time (selection of parameters of competition units was same to that of sample units); then calculated Exp's after competition units were added and repeated the calculation for 10 times.

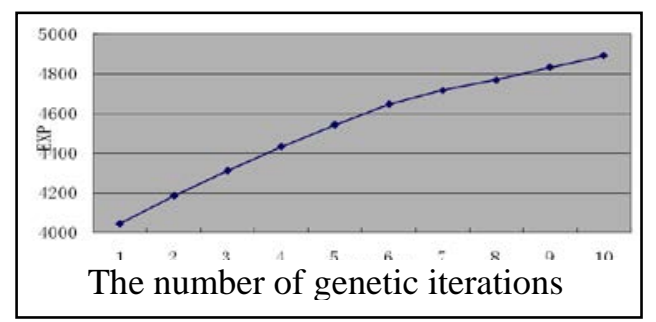

Fig. 1: The change curve of EXP

\section{Analysis of Performance of industrial cluster}

It can be analyzed from the graph that the performance of industrial cluster rises gradually with the increasing of times of iteration, which is also a result of the constant evolution of this model. When resources of industrial cluster are allocated among business units, business units with high resource utilization efficiency and good performance will adapt to the market and environment very well. Since business unites belong to an independent system, their resource allocation is influenced by the cost of the resource market, quantity of resources, benefits generated by resources, support from decision makers to business units and other parameters. Also as a trade-off relation, resource allocation of industrial cluster is also influenced and regulated by above parameters. For example, decision makers will give more support to business units with better economic benefits, which will be helpful for business units to introduce in new technologies and resources and knock out unfavorable resources so as to facilitate the development of business units, continuously modify parameters that are influencing 
them and enhance competitive advantages. To business units with poor economic benefits, however, decision makers will reduce their support; when encountering fierce competition from external competitors, such business units will find it hard to adapt to the competition, decline and finally drop out of the market. Therefore, business units with high adaptability will choose to stay and those that can not adapt to the competition will be knocked out. To seek for better development, those stayed business units will constantly look for an opportunity of new market and promote new products and services. Such practice will in turn facilitate the diversification and heterogeneity of business units and prosperity of industrial cluster. Therefore, the evolution of industrial cluster is a process for business units to continuously choose, mutate and evolve, which is also the mechanism of resource allocation of industrial cluster. Under the function of such resource allocation mechanism, the performance of industrial cluster will be improved constantly.

\section{Conclusion and Policy Suggestions}

Research in this paper has provided new methods and ideas for the transformation and upgrading of industrial cluster. The evolution of industrial cluster and factors that are influencing business units have been analyzed from the perspective of business units; moreover, a tradeoff mechanism of resource allocation has been established and a simulation on the evolution of industrial cluster has been made with genetic algorithm.

Result of this research is guiding significant to the construction of business units in industrial cluster, the transformation and upgrading of industrial cluster and the optimization of performance of industrial cluster. In addition, the result has provided theoretical foundation for the government to formulate industrial policies. In specific, the significance includes:

(1)Cultivate business units to enter and quit the mechanism freely. The government can promote the development of industrial cluster through encouraging and limiting the development of business units and their cooperation. Properly remove barriers in the process of introducing in new business units and solving the problem of internal labors in the process of the exiting of business units; A decision maker should formulate corresponding strategies according to the development stages of business units 。

(2)Improve the ability of business units in dynamic resource allocation. The ability of business units in dynamic resource allocation refers to the ability of constantly modifying parameters that are influencing business units according to the business units themselves and external environment. It is also the tradeoff mechanism of resource allocation which will facilitate the evolution of business units in industrial cluster. Such ability of business units can facilitate innovation of business units through binding and rebinding resources.

This research is an exploratory research on the transformation and upgrading of industrial cluster. Further study is required for exploring issues related to industrial cluster. For example, the genetic algorithm model established in this paper can be applied for studying innovative cooperation among subjects of business units in industrial cluster, constructing a new network and analyzing different effects resulted from different cooperation models among subjects of business units. Another subject to be studied is the influence of social network on behavioral subjects of industrial cluster.

\section{References}

[1] Q. Liu. Research review (J)of industrial cluster upgrading. scientific management, 2007, 28(3) :57-62.

[2] L.X. Mei, B. Cai, M. Nie. The upgrading of the global value chain and the local industrial clusters. scientific management,2005, 26(5) :147-151. 
[3] Y.S. Cheng. from the view of evolutionary economics Research on Sharing knowledge within Enterprise. The national business: economic theory research ,2009(1):33-34

[4] Q.G. Ma, Q. Sheng, D.D. Li, J. Bian. Neurochemical and genetic basis of economic decision-making. Chinese Science Bulletin,2010 , 55 (32): 3089 -3096

[5]Banker, R. D., Bardhan, I. R., \& Chen, T. Y.The role of manufacturing practices in mediating the impact of activity-based costing on plant performance. Accounting, Organizations and Society, 2008(33): 1-19.

[6] C Haslam, N Tsitsianis, T Andersson, YP Yin . Apple's financial success: The precariousness of power exercised in global value chains. Accounting Forum, 2013,37(4): 268-279.

[7] Hou er ju,sheng zheng ping. the characteristics of Industry cluster development in Jiangsu province and dynamic mechanism research, the research of land and natural resources, 2010( 3) : 16-19。

[8] J.I. Wang, W.P. Wang, W.D. Wang. The upgrading of the industrial cluster's endogenous motivation and Mechanism Study, business economics and management, 2013,2,:90-96

[9] Hoskisson R ,Eden L. Lau C. M. and Wright M.. Strategy in emerging markets, Academy of Management Journal , 2000,25: 249-268。

[10] Gupta A , Govindarajan V. Knowledge flows within multinational corporations. Strategic Management Journal, 2000,4:473-496。

[11] Madhok,A. cost,value and foreign market entry mode :the Transaction and the firm, Strategic Management Journal,1997,18:39-61。

[12] Helfat , C. E. Winter, S. G . Untangling dynamic and operational capabilities: strategy for the everechanging world. Strategic Management Journal,2011, 32(11): 1243-1250。

[13] Julia Nieves . Sabine Haller .Building dynamic capabilities through knowledge. resources Management, 2014, 40 ,224-232。

[14] Samina Karim . Business Unit Reorganization and Innovation in New Product. Markets MANAGEMENT SCIENCE, 2009(7),55(7): 1237-1254。

[15] Spicer, A. McDermott, G. and Kogut, B.. Entreprencurship and privatization in Central Europe: the tenuous balance between destruction and creation [J]. Academy of Management Review , 2000 ,25, 630-649

[16] Li B.H., Zhang L., Wang S.L., Tao F., Cao J.W., Jiang X.D., Song X., Chai. a new service-oriented networked.manufacturing model, XD (2010) Cloud manufacturing,2010, 16(1):1-1 